\title{
Anticipatory Cues Differentially Provoke In Vivo Peptidergic and Monoaminergic Release at the Medial Prefrontal Cortex
}

\author{
Zul Merali*, 1,2,3, Judy McIntosh' and Hymie Anisman ${ }^{3,4}$ \\ 'School of Psychology, University of Ottawa, Ottawa, Ontario, Canada; ${ }^{2}$ Department of Cellular and Molecular Medicine, University of Ottawa, \\ Ottawa, Ontario, Canada; ${ }^{3}$ University of Ottawa Institute of Mental Health Research, Ottawa, Ontario, Canada; ${ }^{4}$ Institute of Neuroscience, \\ Carleton University, Ottawa, Ontario, Canada
}

\begin{abstract}
Like primary reinforcers, the anticipation of reward ought to affect neurochemical release in brain regions, such as the medial prefrontal cortex (mPFC), which are associated with appraisal processes. To assess the neurochemical changes associated with anticipation, rats were exposed to the pairing of auditory (60-dB white noise), visual, and olfactory cues with the daily presentation of a palatable snack (Cue Relevant group). Rats of a second group were similarly trained, but for a 2-week period, the snack was no longer provided following cue presentation (Extinction group). In the third condition, the presentation of the snack and cues was uncorrelated (Cue Irrelevant group). Analyses of dialysates collected in vivo from the mPFC revealed that release of corticotropin-releasing hormone (CRH), gastrinreleasing peptide (GRP), and the 5-HT catabolite, 5-hydroxyindole acetic acid (5-HIAA), had increased bilaterally in response to the anticipatory cues, whereas DA release increased only within the right mPFC. In the case of CRH and GRP, these increases were also apparent in the extinction condition, despite the fact that behavioral arousal to the anticipatory cues (increased exploration, rearing, grooming, and vigilance) was only evident in the Cue Relevant condition. In contrast, the elevated DA and 5-HIAA were apparent exclusively in the Cue Relevant condition. Thus, $\mathrm{CRH}$ and GRP systems may serve to allocate salience and/or incentive reward value to biologically significant stimuli or reflect the emotional response to the anticipatory stimulus. The activity of DA and 5-HT neurons, in contrast, is more closely aligned with the cognitive appraisal of predictor stimuli.
\end{abstract}

Neuropsychopharmacology (2004) 29, I409-1418, advance online publication, 24 March 2004; doi: I 0.1038/sj.npp. I30044 I

Keywords: anticipation; incentive motivation; feeding; CRH; GRP; serotonin; dopamine; microdialysis

\section{INTRODUCTION}

Appetitive and aversive events provoke neurochemical changes within the central and peripheral nervous systems, and it might be expected that the anticipation of such events might also promote adaptive neurochemical responses. The medial prefrontal cortex (mPFC) may be particularly important in this regard, given its role in higher cognitive functions (Kalivas and Nakamura, 1999; Van Eden and Buijs, 2000). Indeed, increased mPFC dopaminergic (DA) and serotonergic (5-HT) activity are associated with both aversive (Bray, 2000; Horger and Roth, 1996; Sullivan and Gratton, 1999; Goldstein et al, 1996) and appetitive processes (Bassareo and Di Chiara, 1997; Blackburn et al, 1989; Feenstra and Botterbom, 1996; Jodo et al, 2000;

*Correspondence: Dr Z Merali, Institute of Mental Health Research, Royal Ottawa Hospital Health Care Group, II45 Carling Avenue, Ottawa, Ontario, Canada KIN 6N5, Tel: + 6I3-722-652I, ext 655I, Fax: + 6I3-722-587I, E-mail: merali@uottawa.ca

Received 16 November 2003; revised 27 January 2004; accepted 5 February 2004

Online publication: 18 February 2004 at http://www.acnp.org/citations/ Npp02 $180403527 /$ default.pdf
Nakahara et al, 2000; Pratt and Mizumori, 2001; Richardson and Gratton, 1996; Wise, 2000; Richardson and Gratton, 1998); Interestingly, accumbal DA utilization was more closely aligned with preparatory or anticipatory foodrelated stimuli than with ingestion itself (Blackburn et al, 1989), although DA variations were induced by deviations of expected reward outcomes (eg delaying reward presentation or reducing reward duration) (Richardson and Gratton, 1998). Such effects are not unique to mesolimbic DA circuits, as hypothalamic 5-HT release was also evoked by both food-related cues and food consumption (Hoebel et al, 1989, 1992; Schwartz et al, 1990). Thus, 5-HT neurons may be important in an anticipatory capacity, possibly reflecting incentive motivation, emotional aspects of anticipation, or cognitive information processing.

Corticotropin-releasing hormone (CRH), which has typically been considered in the context of stress, fear, and anxiety (LeDoux, 2000; Davis, 1998), has been implicated in appetitive (ingestive) responses as well (Merali et al, 1998). It would be of considerable interest to determine whether this peptide is also involved in anticipatory processes. Furthermore, gastrin-releasing peptide (GRP), which is activated with food ingestion and 
stimulates hypothalamic-pituitary-adrenal activity (Gibbs et al, 1979; Gibbs and Smith, 1988; Kent et al, 1998; Merali et al, 1999, 2002), is released at the central amygdala in response to both appetitive and aversive stimuli (Merali et al, 1998). Although $\mathrm{CRH}$ and GRP systems may functionally be interlinked (Merali et al, 2002), and receptors for both peptides are expressed within the mPFC (Kroog et al, 1995; Radulovic et al, 1998), limited information is available as to whether these peptides are associated with anticipatory processes.

The current investigation assessed in vivo release of DA, 5-HT, CRH, and GRP at the $\mathrm{mPFC}$ in relation to the 'anticipation' of a palatable snack. Considering that stressor-elicited DA activation at the mPFC is laterally biased (asymmetrical) (Sullivan and Gratton, 1998; Nielsen et al, 1999; Brake et al, 2000; Carlson et al, 1993), we assessed whether anticipatory monoaminergic and/or peptidergic variations were likewise laterally asymmetrical. Importantly, rather than assessing the effects of anticipatory cues in food-deprived animals, we did so in sated rats trained to anticipate a 'palatable snack', thereby circumventing the potentially confounding effects of food deprivation. Finally, in order to ascertain the specificity of the anticipatory neurochemical variations, neurochemical changes were also determined in rats initially trained to anticipate the snack, but then exposed to an extinction regimen.

\section{MATERIALS AND METHODS}

\section{Subjects and Apparatus}

A total of 45 male Long-Evans rats, weighing 275-300 g, were obtained from Charles River Inc (St Constant, Quebec). After arrival in the vivarium, and a mandatory quarantine period, animals were individually housed in custom-designed 'anticipation' cages (clear Plexiglas boxes, $35 \mathrm{~cm} \times 25 \mathrm{~cm} \times 34 \mathrm{~cm}$ with a wire mesh floor and a 'safe' cubicle of black Plexiglas $15 \mathrm{~cm} \times 15 \mathrm{~cm} \times 19 \mathrm{~cm}$ located in one corner of the cage). Cages were equipped with a speaker that delivered $60-\mathrm{dB}$ white noise. Animals were fed ad libitum (except during training and testing) and housed in a quiet room, separated from other animals in the facility, in a controlled environment maintained at $21^{\circ} \mathrm{C}$ with $60 \%$ relative humidity. All experimental procedures followed the Canadian Council on Animal Care guidelines and were approved by the Research Ethics Committee of the University of Ottawa.

\section{Training}

Animals were randomly assigned to three groups and were exposed to their respective training procedures both before stereotaxic surgery and for 2 weeks following recovery. Briefly, animals were weighed each morning, during which their cages were cleaned and their food was removed, so that the presence of the experimenter did not become a conditioned stimulus. Over the next $2-3 \mathrm{~h}$, the experimenter randomly entered and exited the room, mimicking the dialysate sample collection procedure that would subsequently be introduced. Rats in one condition (Cue Relevant group) were presented with compound 'anticipatory' cues that comprised a $60-\mathrm{dB}$ white noise emitted through a speaker located in the cage top coupled with the sight/odor of the snack (two $1.8 \mathrm{~g}$ squares of Graham Wafers) (Christie's Honeymaid $^{\circledR}$ ) placed at the top of each cage, but inaccessible to the rat. On each day (between 1100 and $1300)$, this procedure was repeated for variable time periods (5-40 min) prior to snack delivery, after which rats were given access to the palatable snack and the auditory cue was immediately terminated. These rats received the treatments during the 2-week period preceding surgery and for 2 weeks beginning 5 days after surgery. Rats in a second condition (Extinction group) were similarly trained (exposed to the cues and given access to the snack); however, after 4 weeks of initial training and the surgical procedure, the snack delivery was discontinued for the 2 -week period prior to testing, although the anticipatory cues continued to be presented. Finally, rats in the third condition (Cue Irrelevant group) were presented with the compound stimulus and the snack, but the two were independent (uncorrelated) of one another. This procedure was undertaken for 2 weeks before and 2 weeks after surgery, with the latter commencing after the 5-day surgical recovery period. It will be noted that in well-trained animals, on presentation of a palatable snack rats immediately approached and consumed this food. Moreover, we have observed that when a palatable snack is presented to animals in their living cage, it did not elicit an anxiety-like reaction (although anxiety was provoked when the snack was offered to animals in unfamiliar surroundings) (Merali et al, 2003), and hence the neurochemical effects of this treatment in the present investigation could not be attributed to anxiety effects.

\section{Surgery}

Following the initial 2-week training period, rats were anesthetized using pentobarbital $(60 \mathrm{mg} / \mathrm{kg}$, intraperitoneal) with halothane supplement (1.51) as required, and placed in a stereotaxic instrument with level skull. Blunted ear bars were used in order to protect the rats' eardrums. Two 20gauge guide cannulae, each containing a removable 24gauge stainless-steel obturator, were implanted at the right and left mPFC. The placement coordinates (Paxinos and Watson, 1986) with level skull were anterioposterior $=+3.2$, lateral $= \pm 0.8$, and dorsoventral $=-3.5$ ). The guide cannula (which protruded from a customdesigned Delrin $^{\mathrm{TM}}$ pedestal) was then secured to the skull with four stainless-steel screws and acrylic dental cement.

\section{In Vivo Microdialysis and Behavioral Testing}

At 1 day prior to testing, animals were briefly anesthetized using halothane and the obturators (within the guide cannulae) were replaced with microdialysis probes. The concentric microdialysis probes (with $2 \mathrm{~mm}$ of active membrane; $250 \mu \mathrm{m}$ outer diameter) of regenerated cellulose (6000 Da molecular weight cutoff; Spectrum Medical Industries) were positioned above the target site such that they rested within the guide cannulae. Each probe was secured with a retaining screw and connected via polyethylene tubing (Intermedic, Clay Adams, NJ) to a liquid swivel and a $2.5 \mathrm{ml}$ infusion syringe (Hamilton) attached to 
a pump (model 22, Harvard). Microdialysis probes were perfused overnight at a rate of $0.5 \mu \mathrm{l} / \mathrm{min}$ with filtered $\mathrm{KRB}$ solution consisting of (in $\mathrm{mM}$ ): $\mathrm{K}^{+} 2.7, \mathrm{Na}^{+} 145, \mathrm{Ca}^{2+}$ 1.35, $\mathrm{Mg}^{2+} 1.0, \mathrm{Cl}^{-} 150,(\mathrm{pH}$ 7.4) and BSA (0.1\%) (Moghaddam and Bunney, 1989). On the following morning, animals were gently restrained and probes were lowered into the target position (within the mPFC), and the perfusion rate of the KRB was increased to $3 \mu \mathrm{l} / \mathrm{min}$. Sample collection was initiated $1.5-2 \mathrm{~h}$ later. On collection, each sample $(50-60 \mu \mathrm{l})$ was immediately frozen on dry ice and stored at $-80^{\circ} \mathrm{C}$ until analysis by radioimmunoassay (RIA) and high-performance liquid chromatography (HPLC).

On the test day, the probes were continually perfused with $\mathrm{KRB}$, and dialysates were pooled every $20 \mathrm{~min}$ throughout the experiment. After collecting five baseline samples, all rats were presented with the 'anticipatory' cues, as described earlier, for a 40 min period. Dialysate samples continued to be collected every $20 \mathrm{~min}$. At the end of the 'anticipatory' period, rats of the Cue Relevant group were presented with and allowed to consume the snack, and two dialysate samples were collected during this $40 \mathrm{~min}$ period. For the two remaining groups, the snacks were removed from the top of the cage and discarded, but samples continued to be collected.

\section{Radioimmunoassays}

The detection and quantification of $\mathrm{CRH}$ was achieved through a solid-phase high-sensitivity adaptation/modification (Maidment and Evans, 1991) of the double antibody liquid-phase RIA originally described by Vale et al (1983). BN-LP(s) were detected using a similar solid-phase RIA (Plamondon and Merali, 1997). Briefly, protein A/G (Calbiochem-Novabiochem Corp., La Jolla, CA)-coated Immulon ${ }^{\mathbb{R}}-4$ wells (Dynatech Laboratories, Inc., Chantilly, VA) were incubated with anti-CRH serum (rC70 kindly provided by $\mathrm{W}$ Vale) or anti-BN serum $(\alpha-\mathrm{BN} 2$ kindly provided by $\mathrm{Dr} \mathrm{T}$ Moody) for $2 \mathrm{~h}$ at $20^{\circ} \mathrm{C}$. Samples, standards (reconstituted in the KRB solution with BSA (0.1\%), ranging from 0.05 to $250 \mathrm{fmol} /$ well or blanks, were incubated for $24 \mathrm{~h}$ at $4{ }^{\circ} \mathrm{C}$. Next, $25 \mu \mathrm{l}$ assay buffer containing 5000-6000 cpm [ $\left.{ }^{125} \mathrm{I}_{-\mathrm{Tyr}}{ }^{0}\right] \mathrm{rCRF}$ (Amersham Canada Ltd, Oakville, Ontario) or [ $\left.{ }^{125} \mathrm{I}_{-} \mathrm{Tyr}^{4}\right] \mathrm{BN}$ (iodinated in house, as per Salacinski et al, 1981) was added to each well and incubated for an additional $24-\mathrm{h}$ period at $4^{\circ} \mathrm{C}$. Finally, the wells were rinsed, separated, and their residual radioactivity was counted in a gamma-counter (Cobra ${ }^{\circledR}$ II Auto-gamma, Meriden, CT). A four-parameter logistic curve fit model was used for interpolation of the standard curves. The sensitivity of the assay was typically about 0.1 and $2 \mathrm{fmol} /$ well for CRH and $\mathrm{BN}$, respectively.

The specific anti-CRF serum used in the study recognized $\mathrm{CRH}_{1-41}$ and displayed negligible crossreactivity with other related peptides (Vale et al, 1983), including urotensin 1 and urocortin (data not shown). The BN antibody used in the RIAs recognized the C-terminal fragment of $\mathrm{BN}$ and strongly crossreacts with amphibian $\mathrm{BN}(100 \%)$ and certain mammalian BN-LPs, including GRP $\mathrm{GR}_{1-27}(110 \%)$ and $\mathrm{GRP}_{18-27}$ (neuromedin C or NMC (82\%), but only weakly with GRP ${ }_{1-16}, \mathrm{NMB}-10, \mathrm{NMB}-32$, or substance $\mathrm{P}(\leqslant 0.1 \%)$. We have shown previously that the major source of BN-LP immunoreactivity from the hypothalamus is attributable to GRP (Merali and Kateb, 1993).

\section{High-Performance Liquid Chromatography}

Levels of DA and 5-hydroxyindole acetic acid (5-HIAA) (5-HT was below the detection limit) were determined using an HPLC system (Agilent Technologies, Waldbronn, Germany). Samples were injected (Agilent 1100 series Autosampler, Waldbronn, Germany) into the HPLC system equipped with a single-cell electrochemical detector (Antec Leyden Model Intro, Montreal, PQ, Canada) with an applied potential of $0.650 \mathrm{nA}$, filter of $1 \mathrm{~s}$, and range of $0.1 \mathrm{nA} / \mathrm{V}$. The separation of these analytes was achieved by their passage through an ESA, $4.6 \times 150 \mathrm{~mm}^{2}, 5 \mu \mathrm{m}$ analytical column (Zorbax Eclipse XDB-C8, Agilent Technologies, Waldbronn, Germany). The mobile phase, consisting of $90 \mathrm{mM}$ sodium dihydrogen phosphate (monobasic), $1.7 \mathrm{mM}$ 1-octane sulfonic acid (sodium salt), $50 \mathrm{nM}$ EDTA, $10 \%(200 \mathrm{ml} / 2 \mathrm{l})$ acetonitrile, $50 \mathrm{mM}$ citric acid (monohydrate), and $5 \mathrm{mM}$ $\mathrm{KCl}$ (final $\mathrm{pH}=2.4$ ), was delivered at a flow rate of $1.0 \mathrm{ml} /$ min. Quantification of the various analytes was accomplished by comparing their area under the curve to those of known external standards (calibrated at $2.5 \mathrm{pg} / 50 \mu \mathrm{l}, 5.0 \mathrm{pg} /$ $50 \mu \mathrm{l}$, and $50.0 \mathrm{pg} / 50 \mu \mathrm{l}$ ) using a computerized Agilent ChemStation chromatography data acquisition system (Agilent Technologies, Mississauga, Ontario).

\section{Behavioral Monitoring}

During testing, animals were videotaped and their behaviors were analyzed over a $120 \mathrm{~min}$ time period (during baseline, 'anticipation', and 'wafer' sampling periods). The frequency of sleeping/inactivity, exploring (moving about or actively examining an area of the test environment), rearing, vigilance (alert watchful), and grooming were scored every $10 \mathrm{~s}$. This time sampling procedure has been found, in our laboratory, to provide better than $90 \%$ agreement between independent raters.

\section{Histology}

At the end of the experiment, animals were deeply anesthetized using halothane and decapitated. Their brains were sectioned and stained for histological examination. Only animals with verified placement in the right and left mPFC were used in this study. Of the original 45 animal contingent, 23 animals had both cannulae correctly positioned within the mPFC, 11 had one cannulae correctly positioned (seven in the right hemisphere and four in the left), while 11 animals did not have either cannulae correctly situated.

\section{Statistical Analysis}

The microdialysis data were analyzed by averaging the first three baseline samples (denoted as $100 \%$ ) and subsequent samples expressed as a percent of this baseline. This included the last two of the five baseline samples, the two samples taken during the anticipatory period, and the ensuing two samples when rats in the Cue Relevant group were permitted to consume the snack. The behavioral 
responses (exploring, rearing, grooming, vigilance, and resting/sleeping) and the interstitial levels of CRH, GRP, DA, and 5-HIAA in the mPFC were analyzed by HuynhFeldt corrected mixed measures ANOVAs with Treatment (Cue Relevant, Extinction, Cue Irrelevant) as the betweengroup factor and both Periods (Baseline, anticipatory period and consumption period) and Time (dialysates taken over the $20 \mathrm{~min}$ samples within each period) as the withinsubjects factor. As cannulae placements were not uniformly accurate in both hemispheres, data from rats with only a single accurate placement were included in the analyses, and hence hemisphere (left $v s$ right cannulae placement) was considered a between-group variable. In some instances, procedural difficulties precluded samples being collected and/or analyzed, and hence the degrees of freedom varied across the different amines and peptides. Where a significant interaction was present, follow-up comparisons of the simple effects were conducted by Newman-Keuls multiple comparisons $(\alpha=0.05)$.

\section{RESULTS}

\section{Effect of the Anticipatory Cues and Subsequent Consumption (or not) of a Palatable Snack on the Animals' Behavior}

Figure 1 depicts the frequencies of the animals' behaviors (Cue Relevant, $n=11$; Extinction, $n=10$; Cue Irrelevant, $n=11$ ) in response to the presentation of the 'anticipatory' cues followed by the presentation (or not) of a palatable snack. The behavior of rats in the Cue Relevant group was characterized by alertness during the anticipatory period, whereas in the Extinction and Cue Irrelevant groups this behavioral profile was not evident, thus attesting to the
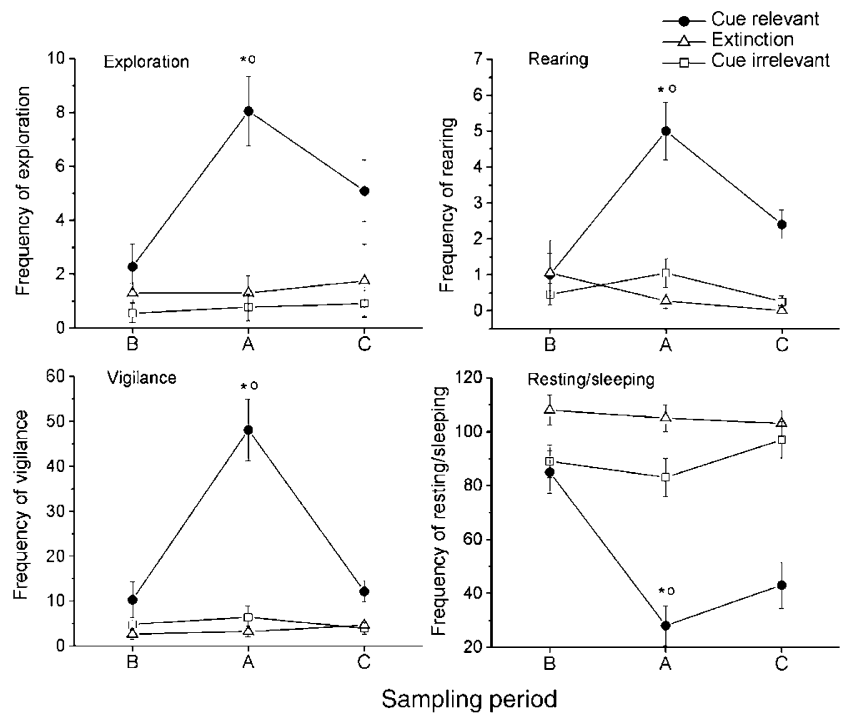

Figure I Frequency (mean \pm SEM) of exploration, rearing, vigilance, and resting/sleeping, using a $10 \mathrm{~s}$ time sampling procedure, among rats in the Cue Relevant, Extinction, and Cue Irrelevant conditions. Behaviors are presented during 20 min periods reflecting a baseline period (B), an anticipation period $(A)$, and following snack presentation in the Cue Relevant group (C). ${ }^{*} p<0.05$ relative to baseline (B5); ${ }^{\circ} p<0.05$ relative to Cue Irrelevant and Extinction groups. apparent efficacy of the training procedure. Figure 1 shows the four most common behaviors (exploration, rearing, vigilance, and resting/sleeping) for each of the groups during the six sampling periods.

The frequency of resting/sleeping varied as a function of the Treatment Condition $\times$ Period $\times$ Sample interaction, $\mathrm{F}_{4,58}=13.33, p<0.001$. During the baseline period, each of the groups spent the greatest proportion of time in a resting/sleeping state. In both the Extinction and Cue Irrelevant conditions, this continued through the remaining phases. In contrast, in the Cue Relevant group, the frequency of resting/sleeping declined markedly during the anticipation period, reaching statistical significance during the second portion of this period and the first portion of the consumption phase. During these times, rats in the Cue Relevant group rested/slept significantly less than did rats in the other two groups (see Figure 1).

The decline of resting/sleeping in the Cue Relevant condition was accompanied by an increase of active behaviors, including exploration, rearing, and vigilance. The ANOVAs revealed significant Treatment Condition $\times$ Period $\times$ Sample time interactions for these behaviors, $F^{\prime} s_{4,58}=6.54,3.16,3.84, p$ 's $<0.001$, respectively. The follow-up tests confirmed that during the anticipatory period, rats in the Cue Relevant group exhibited more exploration, rearing, and vigilant behavior relative to baseline. Moreover, during these periods, rats in the Cue Relevant group displayed significantly more active behaviors than did rats in the extinction or Cue Irrelevant condition (see Figure 1). Furthermore, during the first portion of the consummatory period, the rats in the anticipation group continued to show greater vigilance, exploration, and rearing than rats in the remaining two groups, but by the second sample within this period this activation had dissipated.

\section{Interstitial Levels of CRH and GRP in Anticipation of a Palatable Snack}

Figure 2 depicts the interstitial levels (presented as a percentage of baseline values) of CRH at the mPFC in response to the presentation of the 'anticipatory' cues and during the period associated with consumption (or not) of a palatable snack (Cue Relevant right and left, $n=8$ and 10, respectively; Extinction right and left $n=8$ and 6 , respectively; Cue Irrelevant right and left, $n=6$ and 6 ). The mixed measures ANOVA revealed that among animals with correctly positioned probes, $\mathrm{CRH}$ within the right $\mathrm{mPFC}$ varied as a function of the Treatment Condition $\times$ Period interaction, $\mathrm{F}_{2,38}=4.01, p<0.01$. The follow-up tests of the simple effects comprising this interaction indicated that in the Cue Relevant group and the Extinction condition, a significant rise of interstitial levels of CRH was evident during the 'anticipatory' period relative to their own baseline levels (see Figure 2). In both conditions, the levels of interstitial $\mathrm{CRH}$ remained elevated during the consummatory period, although a significant decline from the anticipatory period was apparent in the Cue Relevant group. Levels of $\mathrm{CRH}$ did not vary over samples in the Cue Irrelevant condition, and consequently, the interstitial CRH levels during the anticipation and consummatory periods in 


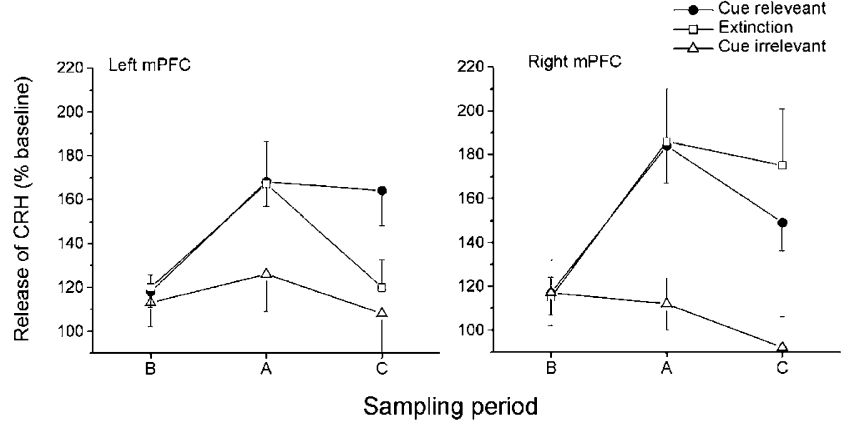

Figure 2 Effect of anticipatory cues and consumption of a palatable snack on the in vivo release of $\mathrm{CRH}$ in the left and right mPFC of rats in the Cue Relevant, Extinction, and Cue Irrelevant conditions. Scores represent the mean $( \pm$ SEM) percentage change from the baseline period. Peptide changes are presented over the $40 \mathrm{~min}$ periods comprising the baseline period (B), the anticipation period (A), and after presentation of the palatable snack in the Cue Relevant group (C). Rats that were trained to 'anticipate' the presentation and consumption of palatable snack (Cue Relevant), similarly trained to anticipate a snack, but for a 2-week period prior to testing the snack presentation was discontinued (Extinction), or had the cues and the snack presented independent of one another (Cue Irrelevant). *Significantly greater than baseline, $(p<0.01)$; ${ }^{\circ}$ significantly greater $(p<0.01)$ than the Cue Irrelevant group.

the Cue Relevant and Extinction groups significantly exceeded that of the Cue Irrelevant group.

Within the left mPFC, the interstitial CRH levels varied as a function of the Treatment Conditions $\times$ Period $\times$ Samples interaction, $\mathrm{F}_{4,38}=2.70, p=0.04$. The profile of $\mathrm{CRH}$ changes was similar to that evident within the right $\mathrm{mPFC}$, although these effects varied over samples within the anticipatory and consummatory phases. Specifically, the follow-up tests indicated that in both the Cue Relevant and Extinction conditions, $\mathrm{CRH}$ was elevated during the anticipation period relative to their own baselines. In the Cue Relevant group, the increase reached statistical significance during the second anticipatory sample, whereas in the extinction condition, the effect was significant during the first anticipatory sample. Whereas the rise was still evident in the Cue Relevant condition during the consummatory period, it fell to baseline levels in the Cue Irrelevant conditions. In contrast to the marked changes evident in the former conditions, CRH did not vary significantly over periods in the Cue Irrelevant group. Indeed, the follow-up comparisons indicated that while baseline CRH did not differ between the groups at baseline, the CRH levels in the Cue Relevant and Extinction groups exceeded that of the Cue Irrelevant group during the first anticipation sample. Also, during the consummatory period, the CRH levels in the Cue relevant group exceeded that of the Cue irrelevant condition, whereas in the extinction condition this increase over the Cue Irrelevant condition was not sustained.

The interstitial levels (presented as a percentage of baseline values) of GRP at the mPFC in response to the presentation of the 'anticipatory' cues followed by the consumption of a palatable snack are shown in Figure 3 (Cue Relevant right and left, $n=7$ and 10, respectively; Extinction right and left $n=8$ and 7, respectively; Cue Irrelevant right and left, $n=7$ /group). The interstitial levels of this peptide varied as a function of the Treatment

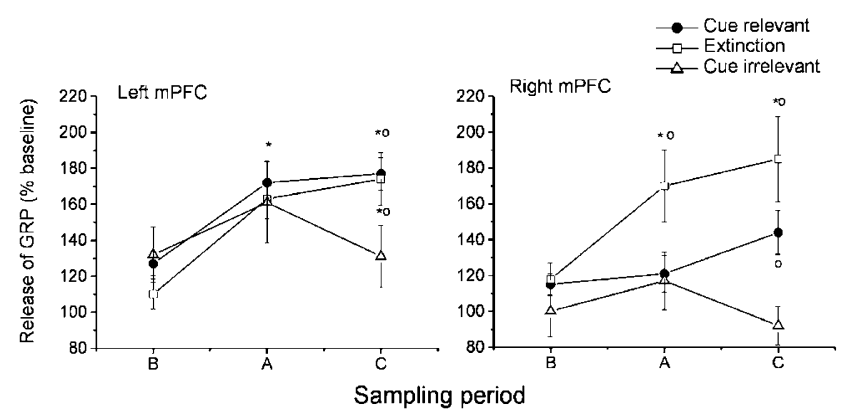

Figure 3 Effect of anticipatory cues and consumption of a palatable snack on the in vivo release of GRP in the left and right mPFC. Scores represent the mean $( \pm S E M)$ percentage change from the baseline period. Peptide changes are presented over the 40 min periods comprising the baseline period (B), the anticipation period (A), and after presentation of the palatable snack in the Cue Relevant group (C). *Significantly greater than baseline $(p<0.01)$; ${ }^{\circ}$ significantly greater $(p<0.01)$ than the Cue Irrelevant group.

Condition $\times$ Period interactions, $\mathrm{F}_{4,38}=2.67$ and 2.60; $p$ 's $<0.05$, for the right and left mPFC, respectively. The subsequent follow-up tests of the simple effects of this interaction confirmed that relative to baseline, in the Cue Relevant group, the anticipatory stimuli did not significantly increase interstitial GRP levels in the right mPFC, although there was an increase of GRP in the left hemisphere. Interestingly, the effects of the anticipatory stimuli on interstitial GRP levels were relatively marked in the Extinction group, where a significant rise of the peptide level was evident during the anticipation period, and continued to remain elevated (in both hemispheres) during the consummatory period. Relative to the levels evident in the Cue Irrelevant condition, in the extinction condition, the rise of GRP during the anticipatory and consumption period was statistically significant in the right mPFC, but owing to a rise in the Cue Irrelevant group during the anticipatory period, between-group differences were noted during the consumption period but not during the anticipatory period. In both hemispheres, the GRP levels in the Cue Relevant condition exceeded that of the Cue Irrelevant condition during the consumption period.

\section{Interstitial Levels of 5-HIAA and DA in Anticipation of a Palatable Snack}

Figure 4 shows the interstitial levels of 5-HIAA at the mPFC (expressed as a percentage of baseline) in response to the presentation of the 'anticipatory' cues followed by the presentation (or not) of a palatable snack (Cue Relevant right and left, $n=10$ and 10, respectively; Extinction right and left $n=8$ and 7, respectively; Cue Irrelevant right and left, $n=9$ and 10, respectively). The accumulation of 5HIAA in both the right and left MPFC varied as a function of the Treatment Condition $\times$ Period interaction, $\mathrm{F}_{4,44}$ and $\mathrm{F}_{4,48}=3.95$ and 3.79, $p$ 's $<0.01$. It appeared from the followup comparisons that in the Cue Relevant group, the interstitial accumulation of 5-HIAA increased during the anticipation period relative to baseline, but declined to baseline levels during the consummatory period. Accumulation of 5-HIAA was not apparent in either the Extinction or the Cue Relevant conditions. The follow-up comparisons 


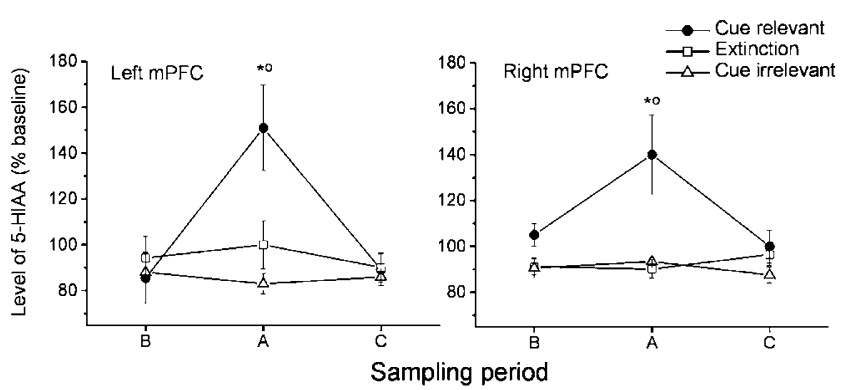

Figure 4 Effect of anticipatory cues and consumption of a palatable snack on the interstitial 5-HIAA levels at the left and right mPFC. Scores represent the mean $( \pm S E M)$ percentage change from the baseline period. Peptide changes are presented over the $40 \mathrm{~min}$ periods comprising the baseline period (B), the anticipation period (A), and after presentation of the palatable snack in the Cue Relevant group (C). *Significantly greater than baseline $(p<0.01)$; ${ }^{\circ}$ significantly greater $(p<0.01)$ than the Cue Irrelevant group.

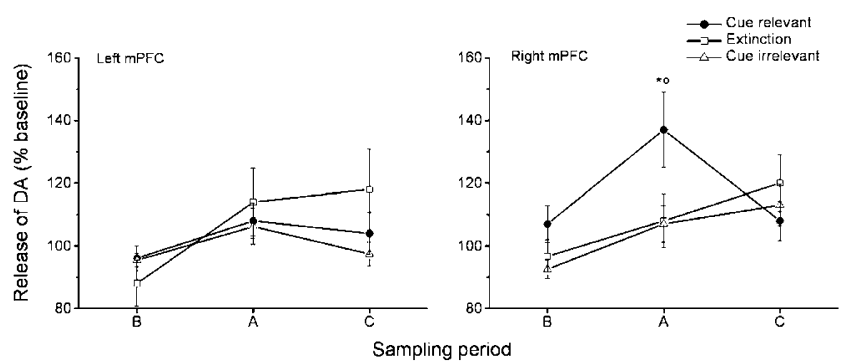

Figure 5 Effect of anticipatory cues and consumption of a palatable snack on the interstitial DA levels at the left and right mPFC. Scores represent the mean $( \pm S E M)$ percentage change from the baseline period. Peptide changes are presented over the 40 min periods comprising the baseline period $(B)$, the anticipation period $(A)$, and after presentation of the palatable snack in the Cue Relevant group (C). *Significantly greater than baseline $(p<0.01)$; ${ }^{\circ}$ significantly greater $(p<0.05)$ than the Cue Irrelevant group

indicated that during the anticipation period, the 5-HIAA levels with the Cue Relevant group exceeded that evident in either of the other groups. The between-group differences were not evident either at baseline or during the consummatory phase.

The DA variations in the right and left mPFC as a function of the treatment conditions are shown in Figure 5 (Cue Relevant right and left, $n=11$ and 10 , respectively; Extinction right and left $n=8$ and 6, respectively; Cue Irrelevant right and left, $n=9$ and 6 , respectively). The interstitial levels of this amine within the right $\mathrm{MPFC}$ were found to vary as a function of the Treatment Condition $\times$ Periods interaction, $\mathrm{F}_{4,50}=2.74, p=0.03$. The followup comparisons confirmed that among rats in the Cue Relevant condition, the presentation of the anticipatory cues resulted in a significant increase of interstitial DA levels relative to baseline, and then declined to baseline levels during the consummatory period. In neither the extinction nor the Cue Irrelevant conditions was interstitial DA found to increase during the anticipation or consummatory periods. As a result, the DA levels during the anticipation period in the Cue Relevant condition significantly exceeded that in the former two conditions.
In contrast to the interstitial DA changes seen in the right mPFC, within the left mPFC, the levels of DA did not vary as a function of the Treatment or condition or the interactions involving this variable. There was a small rise of interstitial DA in the anticipation period (16\%), but this increase was not different from that in the Extinction (15\%) or Cue Irrelevant conditions (6\%).

\section{DISCUSSION}

There have been several reports indicating that appetitive and aversive events may influence DA and 5-HT release in the nucleus accumbens and/or mPFC (eg Richardson and Gratton, 1996, 1998; Sullivan and Gratton, 1998). Also, foodrelated stimuli and changes of expected reward outcomes were found to promote DA changes within the nucleus accumbens (Blackburn et al, 1989; Richardson and Gratton, 1998). While food-related cues were reported to influence 5-HT release, less is known about the influence of anticipatory stimuli on 5-HT changes in limbic regions. Likewise, while $\mathrm{CRH}$ within the amygdala has been implicated in appetitive as well as aversive processes (Merali et al, 1998), it is uncertain whether changes of $\mathrm{CRH}$ are provoked in the mPFC in response to appetitive stimuli or cues that predict reward. Finally, GRP, which acts as a satiety peptide, has been shown to vary in response to food ingestion (Merali et al, 2002), but again, little is known about the GRP response to anticipatory stimuli. The present investigation assessed the influence of ingestion and anticipatory stimuli on neurochemical functioning within the mPFC, specifically whether such effects were unique to particular transmitters (eg variations of GRP, as a satiety peptide, would be aligned with ingestive processes, while DA and 5-HT changes would be evident in response to anticipatory cues).

Exposure to cues that had been paired with access to a palatable snack evoked behavioral signs of arousal. In contrast, when extinction training followed the same initial experience, active behaviors (exploration and vigilance) were no longer elicited by anticipatory stimuli. Instead, rats behaved like animals that had received irrelevant cue training, essentially being inactive most of the time. Thus, the presentation of the 'anticipatory' or incentive stimuli effectively elicited behavioral changes provided that alternative learning (extinction) had not taken place. Parenthetically, in animals with a restricted daily feeding schedule, increased activity is apparent approximately $1-3 \mathrm{~h}$ prior to feeding ('feeding anticipatory activity') (Aragona et al, 2002; Mistlberger and Marchant, 1999; Ono et al, 1996), a behavior that is attenuated by treatment with a 5-HT receptor antagonist (Ono et al, 1996; Shibata et al, 1995; Persons et al, 1993). In the present investigation, the increased activity in the Cue Relevant rats was only evident upon presentation of the anticipatory cues, thus the behavioral and neurochemical changes likely reflected the effects of incentive salience rather than a time-dependent general arousal. However, the possibility cannot be dismissed that the behavioral excitation in the Cue Relevant animals stemmed from frustration, resulting from the long delay ( $40 \mathrm{~min}$ ) between cue presentation and animals actually receiving the snack (Dunn and Berridge, 1990; Heinrichs et al, 1995). 
CRH has frequently been tied to motivational processes, but the influence of this peptide has typically been considered in the context of stressor effects. In this regard, stressor-provoked $\mathrm{CRH}$ variations have been observed at hypothalamic nuclei, the locus coeruleus, central amygdala, bed nucleus of the stria terminalis, as well as the mPFC (Bittencourt and Sawchenko, 2000; Curtis et al, 1995; Davis, 1998; Lavicky and Dunn, 1993). Although CRH receptors are widely distributed throughout the brain, including sites not typically associated with stressors (Potter et al, 1992; Bittencourt and Sawchenko, 2000), relatively little is known with regard to $\mathrm{CRH}$ involvement in behavioral processes such as those related to reward or anticipation of reward (Macey et al, 2000). Nevertheless, it seems that in addition to being activated in response to stressors, CRH release at the central amygdala may also be elicited by ingestion of a palatable snack (Merali et al, 1998). In the present investigation, it was further shown that in response to food-related anticipatory stimuli (Cue Relevant condition), $\mathrm{CRH}$ release increased within the mPFC. Interestingly, among rats that had been exposed to the extinction procedure, increased CRH was still evident upon presentation of anticipatory cues. The fact that this occurred, despite the absence of behavioral arousal, is consistent with the view that these cues maintain incentive value, but the extinction procedure resulted in other behavioral responses being adopted (Nader, 2003; Milad and Quirk, 2002).

Although the satiety effects of GRP (and related peptides, for example, bombesin) have been extensively assessed (Babcock et al, 1985; Gibbs, 1985; Gibbs et al, 1979; Gibbs and Smith, 1988; Merali et al, 1999, 2002), there is a paucity of information concerning the involvement of this peptide in relation to reward or anticipatory mechanisms. In the current investigation, the Cue Relevant and Extinction groups displayed comparable increases of GRP in response to the anticipatory cues; but, in the Cue Relevant group, this increase was most pronounced once rats engaged in actual food ingestion. Curiously, in the Extinction condition, the increase was significant during the 'anticipatory' period. While interesting, these findings are difficult to explain. It has been reported that in rats with stimulating electrodes located in the lateral hypothalamus, intraperitoneal administration of bombesin increased the threshold for stimulation-induced feeding, but did not influence intracranial self-stimulation. Thus, it appeared that the effect of this peptide on stimulation-induced feeding was similar to that of normal feeding (Bushnik et al, 1999). Yet, the finding that GRP release was more pronounced in the Extinction than in the Cue Relevant condition suggests that this peptide is affected by processes unrelated to feeding or satiety per se. Given that GRP is released not only in response to food intake but also in response to stressor application (Kent $\mathrm{et} \mathrm{al}$, 1998; Merali et al, 1998), the possibility exists that the frustration/distress associated with the snack being withheld (in the Extinction condition) was responsible for the increased release of the peptide, even though animals did not show behavioral signs of distress and generally seemed unresponsive in the presence of the cue that had previously been associated with snack delivery.

It has been reported that DA release at the $\mathrm{mPFC}$ and/or the nucleus accumbens was increased among rats responding for food reward (Hernandez and Hoebel, 1988) or in response to relatively novel foods (Ahn and Phillips, 1999; Bassareo and Di Chiara, 1997; Feenstra, 2000; Feenstra and Botterbom, 1996). As DA neuronal activity was also affected by perturbations of expected reward (delaying reward presentation or reducing reward duration), it was suggested that DA neuronal activity operates to influence the incentive value of the food reward (Richardson and Gratton, 1996, 1998). Likewise, the view was offered that the mPFC, in conjunction with $\mathrm{CeA}$, operates to influence the sensory incentive properties of food (Ahn and Phillips, 1999, 2002). Within the present investigation, anticipatory cues were indeed found to affect DA efflux, but this outcome was apparent only within the right mPFC. Within the left mPFC, there was a small rise of DA release in response to anticipatory cues, but this effect did not approach statistical significance.

Several studies have highlighted left/right hemispheric functional asymmetries involving mPFC DA activity following exposure to stressors (Sullivan and Gratton, 2002, 1998; Nielsen et al, 1999; Brake et al, 2000). It was indeed suggested that, depending on the type of stressor involved, the right $\mathrm{mPFC}$ may have a specialized role in the integration of emotional and physiological responses in aversive situations (Sullivan and Gratton, 1998; Brake et al, 2000). Yet, using positron emission tomography, it was shown that stimuli associated with cocaine (which elicit cocaine craving) provoked activation of several sites within the right hemisphere (eg dorsolateral prefrontal cortex) and deactivation of the left frontopolar and mPFC. Thus, an overall bias towards the right hemisphere activation would be elicited by these cues (Bonson et al, 2002). Given that DA variations in the present investigation were only apparent within the right $\mathrm{mPFC}$ suggests that a similar asymmetry also occurs with respect to anticipatory response related to food reward. Importantly, however, the elevated DA release was not evident during the consummatory period. Thus, the possibility exists that the right mPFC DA elevations in response to anticipatory cues may have reflected adverse effects (eg frustration) related to the lengthy period of anticipation $(40 \mathrm{~min})$ prior to actual food delivery.

While it is clear that asymmetry existed with respect to the effects of anticipatory stimuli on DA release, this does not necessarily suggest that DA changes are not elicited in the left mPFC. At this juncture, we can only conclude that the right $\mathrm{mPFC}$ is more sensitive than the left in response to anticipatory cues. Moreover, actual food ingestion did not affect DA release in either hemisphere. It is uncertain whether the absence of more profound DA variations within the left mPFC reflected the fact that animals had been well trained to anticipate the food, hence leading to devaluation of its novelty, or whether it stemmed from relatively transient changes of DA being obfuscated by the fairly long (20 min) sampling periods required for detection of the amine. Further, given that DA changes in the nucleus accumbens and striatum associated with ingestion of a nutritive meal were previously found not to be apparent in response to a palatable non-nutritive saccharin solution (Blackburn et al, 1989), it is similarly possible that such a factor may have limited the MPFC DA changes associated with the palatable snack in rats that had not been food deprived. Also, accumbal DA release was shown to occur in conjunction with the emission of operant responses, rather 
than the actual consumption of food reward (Salamone et al, 1994); thus, it ought to be considered that DA variations within the left mPFC might be associated with actual responding for appetitive reward, rather than anticipatory factors or ingestion per se.

In addition to DA, hypothalamic 5-HT has been implicated in the regulation of food intake (Simansky, 1998). Moreover, the release of this amine is increased in response to food odors or cues that had been paired with food (Hoebel et al, 1989; Schwartz et al, 1990), suggesting that this monoamine may be important in the anticipation associated with food intake. Given that 5-HT receptors modulate cortical DA function in the mPFC (Pehek et al, 2001), and 5-HT has been implicated as a contributing factor in the rewarding effects of psychostimulants (Brown and Molliver, 2000; Kaga et al, 2001), the activity of this amine might have been expected to be influenced by stimuli with incentive properties. Indeed, in the present investigation, 'anticipatory' stimuli increased 5-HIAA accumulation in the Cue Relevant group, just as these stimuli increased $\mathrm{CRH}$ release. However, unlike the $\mathrm{CRH}$ changes, in the Extinction condition, there was no evidence of elevated 5-HIAA or DA in response to the anticipatory stimuli. Thus, greater selectivity was evident with respect to change in these amines than there were with respect to $\mathrm{CRH}$ release. To be sure, accumulation of the 5-HT metabolite, 5-HIAA, does not necessarily reflect the release of 5-HT. Among other things, treatments may affect uptake processes so that the 5-HT and 5-HIAA levels under varied conditions differ from one another. Yet, the fact that the 5-HIAA levels were selectively increased in the Cue Relevant group is consistent with the position that relevant stimuli promoted $5-\mathrm{HT}$ release. That a similar outcome was not apparent in the other two groups cannot necessarily be taken to suggest that increased 5-HT release was not elicited by the treatments, although the data would imply that any such effect is more pronounced in the Cue Relevant condition.

Cues associated with a palatable snack provoked increased activity of $\mathrm{CRH}, 5-\mathrm{HT}$, and DA neurons; however, the functional significance of these neurochemical changes was likely different from one another. Specifically, once animals had learned that the cues no longer predicted snack presentation, the increased $\mathrm{CRH}$ release persisted, whereas that of 5-HT and DA did not. It is conceivable that peptidergic (CRH and possibly GRP) systems serve to allocate salience and/or incentive reward value to biologically significant stimuli or reflect the emotional response to anticipatory stimuli, even after animals have undergone extinction. As indicated earlier, extinction may not eliminate the potential salience of the cues, but rather promotes the adoption of other, more appropriate, responses. In contrast, 5-HT neuronal activity and that of DA within the right MPFC may be more closely aligned with the cognitive appraisal associated with predictor stimuli, such that the increased neuronal activity would be limited to conditions where reward was eminent.

\section{ACKNOWLEDGEMENTS}

This work was supported by grants from the Canadian Institute of Health Research (CIHR) and the Natural
Sciences and Engineering Research Council of Canada (NSERC). HA holds a Canada Research Chair in Neuroscience and is an Ontario Mental Health Senior Research Fellow.

\section{REFERENCES}

Ahn S, Phillips AG (1999). Dopaminergic correlates of sensoryspecific satiety in the medial prefrontal cortex and nucleus accumbens of the rat. J Neurosci 19: RC29.

Ahn S, Phillips AG (2002). Modulation by central and basolateral amygdalar nuclei of dopaminergic correlates of feeding to satiety in the rat nucleus accumbens and medial prefrontal cortex. J Neurosci 22: 10958-10965.

Aragona BJ, Curtis JT, Davidson AJ, Wang Z, Stephan FK (2002). Behavioral and neurochemical investigation of circadian timeplace learning in the rat. J Biol Rhythms 17: 330-344.

Babcock AM, Livosky M, Avery DD (1985). Cholecystokinin and bombesin suppress operant responding for food reward. Pharmacol Biochem Behav 22: 893-895.

Bassareo V, Di Chiara G (1997). Differential influence of associative and nonassociative learning mechanisms on the responsiveness of prefrontal and accumbal dopamine transmission to food stimuli in rats fed ad libitum. J Neurosci 17: 851-861.

Bittencourt JC, Sawchenko PE (2000). Do centrally administered neuropeptides access cognate receptors? An analysis in the central corticotropin-releasing factor system. J Neurosci 20: $1142-1156$.

Blackburn JR, Phillips AG, Jakubovic A, Fibiger HC (1989). Dopamine and preparatory behavior: II. A neurochemical analysis. Behav Neurosci 103: 15-23.

Bonson KR, Grant SJ, Contoreggi CS, Links JM, Metcalfe J, Weyl HL et al (2002). Neural systems and cue-induced cocaine craving. Neuropsychopharmacology 26: 376-386.

Brake WG, Sullivan RM, Gratton A (2000). Perinatal distress leads to lateralized medial prefrontal cortical dopamine hypofunction in adult rats. $J$ Neurosci 20: 5538-5543.

Bray GA (2000). Afferent signals regulating food intake. Proc Nutr Soc 59: 373-384.

Brown P, Molliver ME (2000). Dual serotonin (5-HT) projections to the nucleus accumbens core and shell: relation of the 5-HT transporter to amphetamine-induced neurotoxicity. J Neurosci 20: 1952-1963.

Bushnik T, Bielajew C, Konkle AT, Merali Z (1999). Influence of bombesin on threshold for feeding and reward in the rat. Acta Neurobiol Exp 59: 295-302.

Carlson JN, Fitzgerald LW, Keller Jr RW, Glick SD (1993). Lateralized changes in prefrontal cortical dopamine activity induced by controllable and uncontrollable stress in the rat. Brain Res 630: 178-187.

Curtis AL, Pavcovich LA, Grigoriadis DE, Valentino RJ (1995). Previous stress alters corticotropin-releasing factor neurotransmission in the locus coeruleus. Neuroscience 65: 541-550.

Davis M (1998). Are different parts of the extended amygdala involved in fear versus anxiety? Biol Psychiatry 44: 1239-1247.

Dunn AJ, Berridge CW (1990). Physiological and behavioral responses to corticotropin-releasing factor administration: is CRF a mediator of anxiety or stress responses? Brain Res Rev 15: 71-100.

Feenstra MG (2000). Dopamine and noradrenaline release in the prefrontal cortex in relation to unconditioned and conditioned stress and reward. Prog Brain Res 126: 133-163.

Feenstra M, Botterbom M (1996). Rapid sampling of extracellular dopamine in the rat prefrontal cortex during food consumption, handling and exposure to novelty. Brain Res 742: $17-24$. 
Gibbs J (1985). Effect of bombesin on feeding behavior. Life Sci 37: 147-153.

Gibbs J, Fauser DJ, Rowe EA, Rolls BJ, Rolls ET, Maddison SP (1979). Bombesin suppresses feeding in rats. Nature 282: 208-210.

Gibbs J, Smith GP (1988). The Actions of bombesin-like peptides on food intake. Ann NY Acad Sci 547: 210-216.

Goldstein LE, Rasmusson AM, Bunney BS, Roth RH (1996). Role of the amygdala in the coordination of behavioral, neuroendocrine, and prefrontal cortical monoamine responses to psychological stress in the rat. J Neurosci 16: 4787-4798.

Heinrichs SC, Menzaghi F, Pich EM, Britton KT, Koob GF (1995). The role of CRF in behavioral aspects of stress. Ann NY Acad Sci 771: 92-104.

Hernandez L, Hoebel BG (1988). Feeding and hypothalamic stimulation increase dopamine turnover in the accumbens. Physiol Behav 44: 599-606.

Hoebel BG, Hernandez L, Schwartz DH, Mark GP, Hunter GA (1989). Microdialysis studies of brain norepinephrine, serotonin, and dopamine release during ingestive behavior. Theoretical and clinical implications. Ann NY Acad Sci 575: 171-191.

Hoebel BG, Leibowitz SF, Hernandez L (1992). Neurochemistry of anorexia and bulimia. In: Anderson GH, Kennedy SH (eds). The Biology of Feast and Famine: Relevance to Eating Disorders. Academic Press, Inc.: San Diego. pp 21-45.

Horger BA, Roth RH (1996). The role of mesoprefrontal dopamine neurons in stress. Crit Rev Neurobiol 10: 395-418.

Jodo E, Suzuki Y, Kayama Y (2000). Selective responsiveness of medial prefrontal cortex neurons to the meaningful stimulus with a low probability of occurrence in rats. Brain Res 856: 68-74.

Kaga T, Fujimiya M, Inui A (2001). Emerging functions of neruopeptide $\mathrm{Y} \mathrm{Y}_{2}$ receptors in the brain. Peptides 22: 501-506.

Kalivas PW, Nakamura M (1999). Neural systems for behavioral activation and reward. Curr Opin Neurobiol 9: 223-227.

Kent P, Anisman H, Merali Z (1998). Are bombesin-like peptides involved in the mediation of stress response? Life Sci 62: 103-114.

Kroog GS, Jensen RT, Battey JF (1995). Mammalian bombesin receptors. Med Res Rev 15: 389-417.

Lavicky J, Dunn AJ (1993). Corticotropin-releasing factor stimulates catecholamine release in hypothalamus and prefrontal cortex in freely moving rats as assessed by microdialysis. J Neurochem 60: 602-612.

LeDoux JE (2000). Emotion circuits in the brain. Annu Rev Neurosci 23: 155-184.

Macey DJ, Koob GF, Markou A (2000). CRF and urocortin decreased brain stimulation reward in the rat: reversal by a CRF receptor antagonist. Brain Res 866: 82-91.

Maidment NT, Evans CJ (1991). Measurement of extracellular neuropeptides in the brain: microdialysis linked to solid-phase radioimmunoassays with sub-femtomole limits of detection. In: Robinson TE, Justice JB (eds). Microdialysis in the Neurosciences. Elsevier: Amsterdam. pp 275-303.

Merali Z, Kateb CC (1993). Rapid alterations of hypothalamic and hippocampal bombesin-like peptide levels with feeding status. Am J Physiol 265: R420-R425.

Merali Z, Kent P, Anisman H (2002). Role of bombesin-related peptides in the mediation or integration of the stress response. Cell Mol Life Sci 59: 272-287.

Merali Z, Levac C, Anisman H (2003). Validation of a simple, ethologically relevant paradigm for assessing anxiety in mice. Biol Psychiatry 54: 552-565.

Merali Z, McIntosh J, Anisman H (1999). Role of bombesin-related peptides in the control of food intake. Neuropeptides 33: 376-386.

Merali Z, McIntosh J, Kent P, Michaud D, Anisman H (1998). Aversive and appetitive events evoke the release of corticotropin- releasing hormone and bombesin-like peptides at the central nucleus of the amygdala. J Neurosci 18: 4758-4766.

Milad MR, Quirk GJ (2002). Neurons in medial prefrontal cortex signal memory for fear extinction. Nature 420: 70-74.

Mistlberger RE, Marchant EG (1999). Enhanced food-anticipatory circadian rhythms in the genetically obese Zucker rat. Physiol Behav 66: 329-335.

Moghaddam B, Bunney B (1989). Ionic composition of microdialysis perfusing solution alters the pharmacological responsiveness and basal outflow of striatal dopamine. J Neurochem 53: 652-654.

Nader K (2003). Memory traces unbound. Trends Neurosci 26: 65-72. Nakahara D, Nakamura M, Furukawa H, Furuno N (2000). Intracranial self-stimulation increases differentially in vivo hydroxylation of tyrosine but similarly in vivo hydroxylation of tryptophan in rat medial prefrontal cortex, nucleus accumbens and striatum. Brain Res 864: 124-129.

Nielsen DM, Crosley KJ, Keller Jr RW, Glick SD, Carlson JN (1999). Left and right 6-hydroxydopamine lesions of the medial prefrontal cortex differentially affect voluntary ethanol consumption. Brain Res 823: 59-66.

Ono M, Shibata S, Minamoto Y, Watanabe S (1996). Effect of the noncompetitive $N$-methyl-D-aspartate (NMDA) receptor antagonist MK-801 on food-anticipatory activity rhythm in the rat. Physiol Behav 59: 585-589.

Paxinos G, Watson C (1986). The Brain in Stereotaxic Coordinates. Academic: New York.

Pehek EA, McFarlane HG, Maguschak K, Price B, Pluto CP (2001). $\mathrm{M} 100,907$, a selective $5-\mathrm{HT}_{2 \mathrm{~A}}$ antagonist, attenuates dopamine release in the rat medial prefrontal cortex. Brain Res 888: 51-59.

Persons JE, Stephan FK, Bays ME (1993). Diet-induced obesity attenuates anticipation of food access in rats. Physiol Behav 54: $55-64$.

Plamondon H, Merali Z (1997). Regulation of ingestion by CRF and bombesin-like peptides: distinct meal-related peptide level changes. Am J Physiol 272: R268-R274.

Potter E, Behan DP, Linton EA, Lowry PJ, Sawchenko PE, Vale WW (1992). The central distribution of a corticotropin-releasing factor (CRF)-binding protein predicts multiple sites and modes of interaction with CRF. Proc Natl Acad Sci USA 89: 4192-4196.

Pratt WE, Mizumori SJ (2001). Neurons in rat medial prefrontal cortex show anticipatory rate changes to predictable differential rewards in a spatial memory task. Behav Brain Res 123: 165-183.

Radulovic J, Sydow S, Spiess J (1998). Characterization of native corticotropin-releasing factor receptor type 1 (CRFR1) in the rat and mouse central nervous system. J Neurosci Res 54: 507-521.

Richardson NR, Gratton A (1996). Behavior-relevant changes in nucleus accumbens dopamine transmission elicited by food reinforcement: an electrochemical study in rat. J Neurosci 16: 8160-8169.

Richardson NR, Gratton A (1998). Changes in medial prefrontal cortical dopamine levels associated with response-contingent food reward: an electrochemical study in rat. J Neurosci 18: 9130-9138.

Salacinski PR, McLean C, Sykes JEC, Clement-Jones VV, Lowry PJ (1981). Iodination of proteins, and peptides using solid-phase oxidizing agent, 1,3,4.6-tetrachloro-3,6-diphenyl glucoluril (iodogen) radioiodine into proteins and peptides without damage. Anal Biochem 117: 136-146.

Salamone JD, Cousins MS, McCullough LD, Carriero DL, Berkowitz RJ (1994). Nucleus accumbens dopamine release increases during instrumental lever pressing for food but not free food consumption. Pharmacol Biochem Behav 49: 25-31.

Schwartz DH, Hernandez L, Hoebel BG (1990). Serotonin release in lateral and medial hypothalamus during feeding and its anticipation. Brain Res Bull 25: 797-802.

Shibata S, Ono M, Fukuhara N, Watanabe S (1995). Involvement of dopamine, $N$-methyl-D-aspartate and sigma receptor 
mechanisms in methamphetamine-induced anticipatory activity rhythm in rats. J Pharmacol Exp Ther 274: 688-694.

Simansky KJ (1998). Serotonin and the Structure of Satiation. In: Smith GP (ed). Satiation: From Gut to Brain. Oxford University Press: New York. pp 217-262.

Sullivan RM, Gratton A (1998). Relationships between stressinduced increases in medial prefrontal cortical dopamine and plasma corticosterone levels in rats: role of cerebral laterality. Neuroscience 83: 81-91.

Sullivan RM, Gratton A (1999). Lateralized effects of medial prefrontal cortex lesions on neuroendocrine and autonomic stress responses in rats. J Neurosci 19: 2834-2840.
Sullivan RM, Gratton A (2002). Behavioral effects of excitotoxic lesions of ventral medial prefrontal cortex in the rat are hemisphere-dependent. Brain Res 927: 69-79.

Vale W, Vaughan J, Yamamoto G, Bruhn T, Douglas C, Dalton D et al (1983). Assay of corticotropin releasing factor. Methods Enzymol 103: 565-577.

Van Eden CG, Buijs RM (2000). Functional neuroanatomy of the prefrontal cortex: autonimic interactions. Prog Brain Res 126: 49-62.

Wise RA (2000). Interactions between medial prefrontal cortex and meso-limbic components of brain reward circuitry. Prog Brain Res 126: 255-262. 